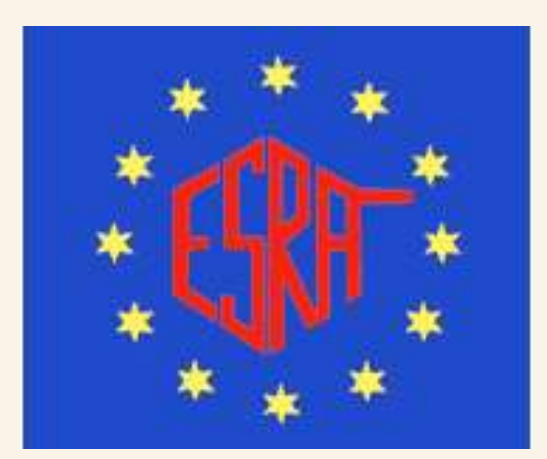

\title{
ULTRASOUND ASSISTED THORACIC EPIDURAL FOR OESOPHAGEAL ATRESIA WITH TRACHEO- OESOPHAGEAL FISTULA REPAIR SURGERY
}

\author{
Alper Tunga DOGAN*, Sami Kaan COSARCAN ***, Omur ERCELEN** \\ Department of Anesthesiology, Amerikan Hospital Istanbul Turkey \\ *DESA-Anesthesiology Specialist, **Professor,***Anesthesiology Specialist
}

\section{Introduction}

Anesthesia management of oesophageal atresia with tracheooesophageal fistula (TOF) repair is a challenge. There are things we should be careful about during pre-per and post-operative period. We report a 48 hour-old neonate, 3050g (>75percentile) scheduled for TOF repair.

\section{Case}

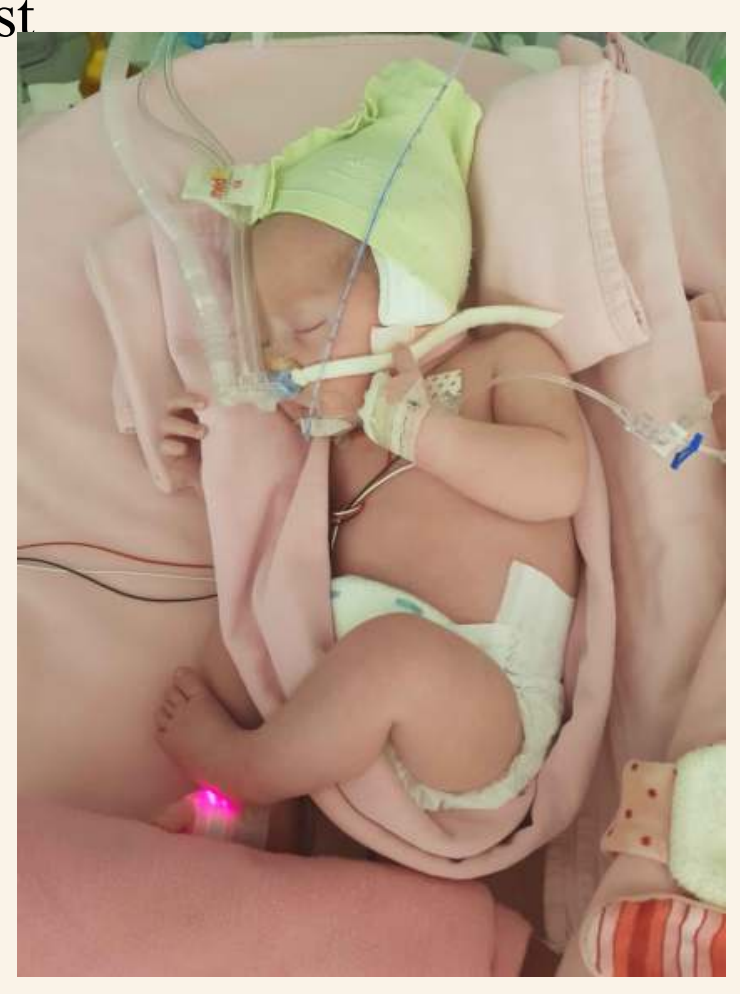

Patient was born at $37^{\text {th }}$ week gestation. He was diagnosed at antepartum period. There were no other coexisting anomalies found. There was a Type-C TOF (fistula exists between the trachea and the lower oesophageal segment above the carina while the upper oesophageal pouch ends blindly in the mediastinum). All oral feeds are stopped, the neonate is kept in upright positioning, and intermittent suctioning of the upper oesophageal pouch is performed to decrease the accumulation of saliva.

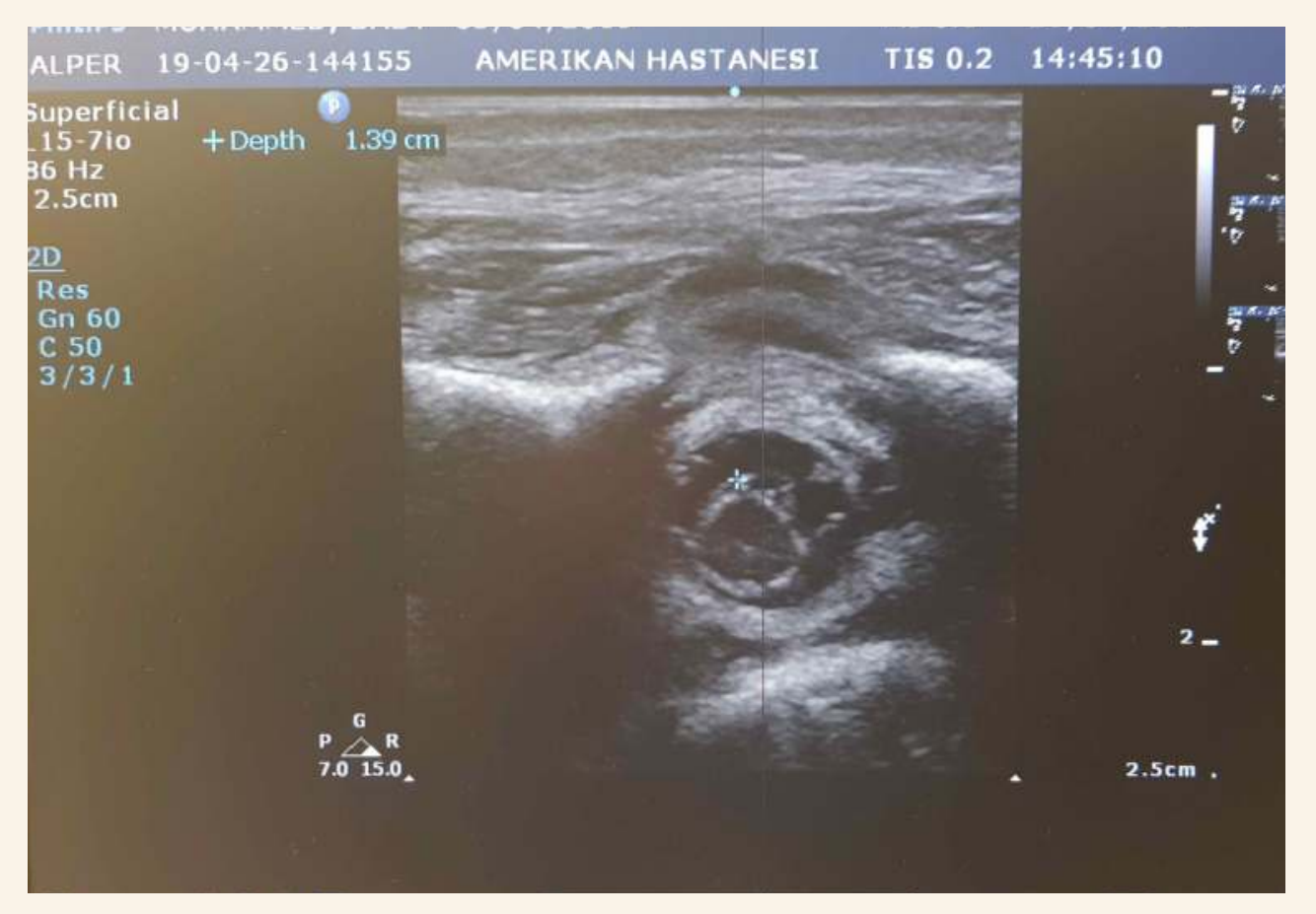

Anesthetic plan is combined anesthesia with a thoracic epidural catheter. After routine monitoring general anesthesia induced with sevoflurane \%3. While maintaining spontaneous ventilation and then the surgeon perform a rigid bronchoscopy determinde that the fistula is at most distal part of the carina. Endotracheal tube is placed and try to preserve spontaneous ventilation so not to inflate the stomach. Within right lateral position ultrasonographic examination done, anatomic structures and epidural depth is defined. Epidural space is determined at $1,3 \mathrm{~cm}$ depth with loss of air method through $20 \mathrm{G}$ toughy needle. Epidural catheter was placed at 6th thoracic level. \%0,1 bupivacaine $1 \mathrm{ml}$ is given for epidural anesthesia. Sevoflurane is reduced to $\% 1,5$ during surgery. During right thoracotomy surgeon requested musclerelaxation. Surgery took 180 minutes. Because it was a complex TOF repair patient transfered intubated to the neonatal intensive care unit.

During postoperative period \%0,1 bupivacaine 1,5ml.h-1 infusion started. Minimal sedation needed. Two attempts of extubation failed because of stridor and forced ventilation. Patient extubated at 5th postoperative day and continued with nasal CPAP. Epidural catheter taken out at 5 th postoperative day.

\section{Conclusion}

Regional anesthesia reduces stress response and sedation requirements in neonates. Ultrasonography is a valuable tool for neuroaxial techniques especially for neonates. With the aid of ultrasonography, failure rates and complications are also reduced. 